\title{
Drug Repurposing Approach Identifies a Synergistic Drug Combination of an Antifungal Agent and an Experimental Organometallic Drug for Melanoma Treatment
}

\author{
Tina Riedel, ${ }^{\dagger}$ Olivier Demaria, ${ }^{\dagger}$ Olivier Zava, ${ }^{\dagger}$ Ana Joncic, ${ }^{\ddagger}$ Michel Gilliet, ${ }^{*}+\underset{*}{ }$ and Paul J. Dyson ${ }^{*},{ }^{\dagger}$
}

${ }^{\dagger}$ Laboratory of Organometallic and Medicinal Chemistry, Institute of Chemical Sciences and Engineering, Swiss Federal Institute of Technology (EPFL), 1015 Lausanne, Switzerland

${ }^{\ddagger}$ Department of Dermatology, University Hospital of Lausanne, 1011 Lausanne, Switzerland

\author{
Supporting Information
}

\begin{abstract}
By screening a drug library comprising FDA approved compounds, we discovered a potent interaction between the antifungal agent haloprogin and the experimental organometallic drug RAPTA-T, to synergistically induce cancer cell killing. The combination of these two small molecules, even at low doses, elicited an improved therapeutic response on tumor growth over either agent alone or the current treatment used in the clinic in the highly aggressive syngeneic B16F10 melanoma tumor model, where classical

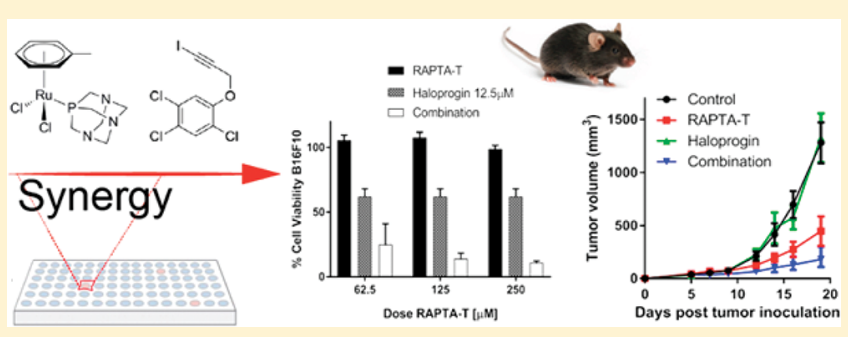
cytotoxic chemotherapeutic agents show little efficacy. The combination with the repurposed chemodrug haloprogin provides the basis for a new powerful treatment option for cutaneous melanoma. Importantly, because synergistic induction of tumor cell death is achieved with low individual drug doses, and cellular targets for RAPTA-T are different from those of classical chemotherapeutic drugs, a therapeutic strategy based on this approach could avoid toxicities and potentially resistance mechanisms, and could even inhibit metastatic progression.
\end{abstract}

KEYWORDS: drug discovery, organometallic drug, antifungal agent, RAPTA-T, haloprogin, high-throughput screening, melanoma

\section{INTRODUCTION}

Chemotherapy is a crucial part of the treatment plan for thousands of patients with various early and late stage cancers. The majority of drugs currently used in cancer chemotherapy are cytotoxic drugs that share a similar mechanism of action; specifically targeting dividing cells by interfering with DNA synthesis, the DNA repair system or mitosis. ${ }^{1,2}$ Their mechanism of action, therefore, does not distinguish between normal and cancerous proliferating cells, a primary cause of side effects, such as bone marrow suppression and dose-limiting toxicities. ${ }^{3}$ Another drawback that limits the use of current chemotherapeutic drugs is the development of drug resistance. ${ }^{4}$ A possible way to advance cancer chemotherapy is to use combinations of drugs in order to improve their therapeutic effects by inhibiting parallel pathways, potentially reducing the incidence of drug-induced resistance. In addition, the administration of drugs that act in an additive or synergistic manner allows scaling down the drug dosage and thereby decreasing toxicity; an approach that is already widely applied in clinic. ${ }^{5-7}$ At the same time, there are many cancer types for which treatment is limited or still nonexistent today, underlining the need for new chemotherapeutic drugs or other treatment options.

Prompted by the success as well as the limitations in the use of the chemotherapeutic agent cisplatin, several nonplatinum metal-based compounds have been developed to produce less toxic drug candidates that overcome cisplatin resistance. Organometallic ruthenium compounds have emerged as promising alternatives to currently used anticancer drugs by displaying specific activities against different cancers and favorable toxicity and clearance properties..$^{8-10}$ Many studies indicate that the mechanism of action of such ruthenium compounds is substantially different to platinum-based drugs, with other biomolecules, beyond DNA, being the primary targets. ${ }^{11-13}$ Our laboratory has developed bifunctional ruthenium agents of the type $\left[\mathrm{Ru}\left(\eta^{6}\right.\right.$-arene $\left.) \mathrm{Cl}_{2}(\mathrm{PTA})\right]$ (where arene $=$ benzene, toluene, p-cymene, etc.), ${ }^{14}$ with RAPTA-T (where the arene = toluene) being one of them, that exhibits low cytotoxicity in cell culture experiments, but is proficient at inhibiting both primary tumor growth and the spreading and growth of solid metastatic tumors in mice. ${ }^{15}$ Experimental data demonstrate that ruthenium compounds are able to sensitize cancer cells to drug-mediated apoptosis. ${ }^{16,17}$ Based on these findings, there is great hope in a combination therapy where RAPTA-T and another drug could combine their effects by acting synergistically and lead to their use in

Received: September 5, 2017

Revised: November 27, 2017

Accepted: November 29, 2017

Published: November 29, 2017 
much lower concentrations that would cause greatly reduced harm to healthy, noncancerous cells.

Several studies have assessed the potential anticancer properties of existing drugs and natural compounds that were initially used for the treatment of non-neoplastic diseases. ${ }^{18-23}$ One recent study identified compounds from a pool of drugs approved for other applications, that when combined with the ruthenium compound NAMI-A led to improved cancer cell killing. ${ }^{17}$ This so-called repurposing or repositioning approach of existing drugs has the advantage that through preceding research and development efforts, the pharmacology, formulation and toxicology of these agents in humans is established, which would reduce the time and cost of approving those compounds for clinical use in cancer therapy. ${ }^{24}$

With this objective, we designed an in vitro high-throughput screen (HTS) with a library of clinically approved drugs to identify novel anticancer agents that interact synergistically with a low concentration of the experimental anticancer metallodrug RAPTA-T to induce cancer cell killing. We show that the antifungal agent, Haloprogin, together with RAPTA-T interact synergistically to kill a variety of cancer cell types. Taking the HTS approach as starting point to assess good drug combinations with RAPTA-T, we further studied the applicability and effectiveness of the RAPTA-T/haloprogin drug combination in vivo in an invasive mouse melanoma model and explored whether the therapeutic efficacy of RAPTA-T was promoted by immunogenic cell death. Our results demonstrate that RAPTA-T alone is highly efficient in inhibiting melanoma tumor growth at low concentrations. The combination of RAPTA-T and haloprogin leads to an improved therapeutic response over either agent alone and represent a novel option for both classes of compounds in melanoma, and potentially other cancer therapy.

\section{EXPERIMENTAL SECTION}

Cells, Culture Conditions, Compounds. B16F10 cells were obtained from the American Type Culture Collection (ATCC) and cultured in Glutamax RPMI (Life Technologies, Switzerland) supplemented with $10 \%$ (v/v) FBS (PAN Biotech, Germany) and $1 \mathrm{mM}$ penicillin/streptomycin. Human breast adenocarcinoma MDA-MB-231 (ATCC) cancer cells were cultured in Glutamax DMEM medium (Life Technologies, Switzerland) supplemented with $10 \%$ fetal bovine serum. Tumor cells were grown in monolayers at 37 ${ }^{\circ} \mathrm{C}$ in a humidified $\mathrm{CO}_{2}$ incubator. Before reaching confluence, B16F10 cells were harvested with enzyme-free cell dissociation buffer (EMD Millipore, Sigma-Aldrich, Switzerland), washed, and suspended in PBS for injection. RAPTA-T was synthesized as previously described. ${ }^{15}$ Haloprogin was purchased from Sigma-Aldrich (Switzerland). The Prestwick Chemical Library was purchased from Prestwick Chemical (Washington, DC) and comprises 1280 small molecules, of which $90 \%$ are FDA approved drugs, supplied at a concentration of $10 \mathrm{mM}$ in DMSO.

Prestwick Chemical Library High-Throughput Screen. The Prestwick chemical library (PCL) (Prestwick Chemical, France) used in this screen is composed of 1280 off-patent and approved small molecule drugs of wide pharmacological diversity. Plates were prepared in duplicates on which each molecule was tested once. Negative control wells (16/384 per assay plate) contained cells treated with $0.01 \%$ DMSO (final concentration) and positive control wells (16/384 per assay plate) contained cells treated with $\mathrm{CuSO}_{4}$ (Sigma-Aldrich) at
$10 \mu \mathrm{M}$. Dilution plates were prepared from original stock plates $(10 \mathrm{mM})$ in $100 \%$ DMSO by diluting the library with $\mathrm{H}_{2} \mathrm{O}$ to $10 \mu$ M. 384 well plates (Corning 3701, Switzerland) used for the assay were prepared by the addition of $3 \mu \mathrm{L}$ of $10 \mu \mathrm{M}$ drug to each well followed by the addition of $3 \mu \mathrm{L}$ of RAPTA-T solution (50 $\mu \mathrm{M}$ in respective cell culture medium) or $3 \mu \mathrm{L}$ of medium. Twenty-four microliters of cell suspension (10000 cells) per well were added. After incubation for $24 \mathrm{~h}$ at $37^{\circ} \mathrm{C}, 3$ $\mu \mathrm{L}$ of PrestoBlue reagent (Thermo Fisher Scientific, Switzerland) was added to each well and the plates were incubated for $1 \mathrm{~h}$ in a cell incubator. The fluorescence intensity was quantified using a multiwell plate reader (ex560 nm/em590 $\mathrm{nm}$, Tecan Infinite F500). The results from the screens were normalized to the controls for every plate and presented as HTS scores, where a score of 0 corresponds to the average fluorescence intensity of the negative control wells (and denotes no cytotoxic activity) and a score of 1 to that of the positive control wells, indicating very active compounds. Compounds were identified and statistically validated as PCL hits when their HTS scores were higher than the average of the negative controls $+3 \times$ SD. Compounds out of the PCL hits were identified as final hits when their average relative viability levels were 1.5 times lower in the presence of RAPTA-T than the respective average viability levels without RAPTA-T. An inhouse Laboratory Information Management System (LIMS) was used for basic data processing, management, visualization, and statistical hit validation.

The quality of the assay was estimated by calculating a $Z^{\prime}$ factor ${ }^{25}$ in which the maximal signal was defined as the viability of cells treated with RAPTA-T $(50 \mu \mathrm{M})$ relative to the positive control $\left(\mathrm{CuSO}_{4}, 10 \mu \mathrm{M}\right)$, and the minimum signal was defined as the background expressed by the positive control (100\% inhibition). The formula used to calculate the $\mathrm{Z}^{\prime}$-factor is $1-$ $3\left(\mathrm{SD}_{\max }-\mathrm{SD}_{\min }\right) /\left(X_{\max }-X_{\min }\right)$, where $\mathrm{SD}$ and $X$ are the standard deviation and average, respectively, of the maximal signal $(\max )$ and the minimum signal $(\mathrm{min})$. Signal-to-noise ratio $(\mathrm{S} / \mathrm{N})$ was calculated using the following formula: $\mathrm{S} / \mathrm{N}=$ $\left(X_{\max }-X_{\min }\right) / \mathrm{SD}_{\min }$. The $\mathrm{Z}^{\prime}$-factor and $\mathrm{S} / \mathrm{N}$ were determined in 384-well plate formats in which half the plate was dosed with RAPTA-T $(50 \mu \mathrm{M})$ and half was dosed with the positive control alone. The determined $\mathrm{Z}^{\prime}$ factor for this assay was 0.70 and the $\mathrm{S} / \mathrm{N}$ ratio 298.

Cell Viability Assay. The PrestoBlue Cell Viability Assay (Thermo Fisher Scientific, Switzerland) was used to determine the effects of monotreatment RAPTA-T, monotreatment haloprogin, or combination treatment RAPTA-T and haloprogin on cancer cell proliferation. B16F10 cells were plated at a density of $1.0 \times 10^{4}$ cells per well, in 96-well plates, and then treated with RAPTA-T or haloprogin over a concentration range from 12.5 to $800 \mu \mathrm{M}$ for RAPTA-T and 5 to $50 \mu \mathrm{M}$ for haloprogin for $72 \mathrm{~h}$. For the combination assays, cells were treated with premixed concentrations of Haloprogin (25, 12.5, $6.25 \mu \mathrm{M})$ and RAPTA-T $(500,250,125$, and $62.5 \mu \mathrm{M})$. At the end of treatments, $20 \mu \mathrm{L}$ of the Presto Blue reagent were added to each well. The plates were then incubated for $2 \mathrm{~h}$ at $37^{\circ} \mathrm{C}$ in the dark. All values were normalized with respect to the viability of untreated cells. Four parameter dose-response curves were created by using a variable slope model with GraphPad Prism 7.02 .

Animal Experiments. Female C57BL/6 mice of age 5-6 weeks were purchased from Charles River, France. All animal experiments were approved by the Institutional Animal Care and Use Committee of the University of Lausanne. All 
A

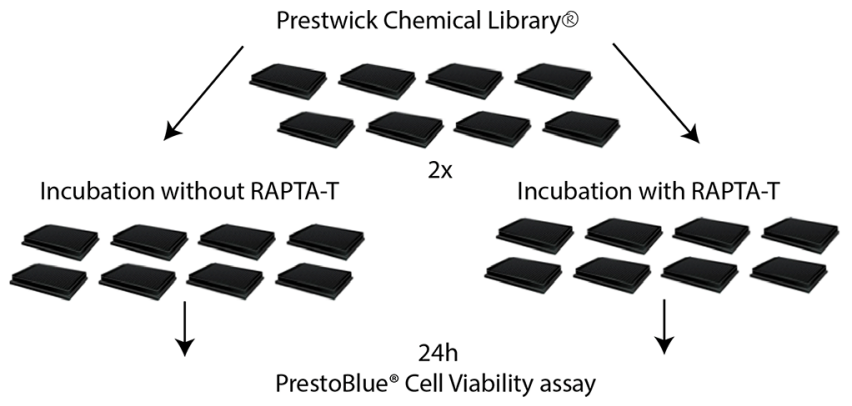

B
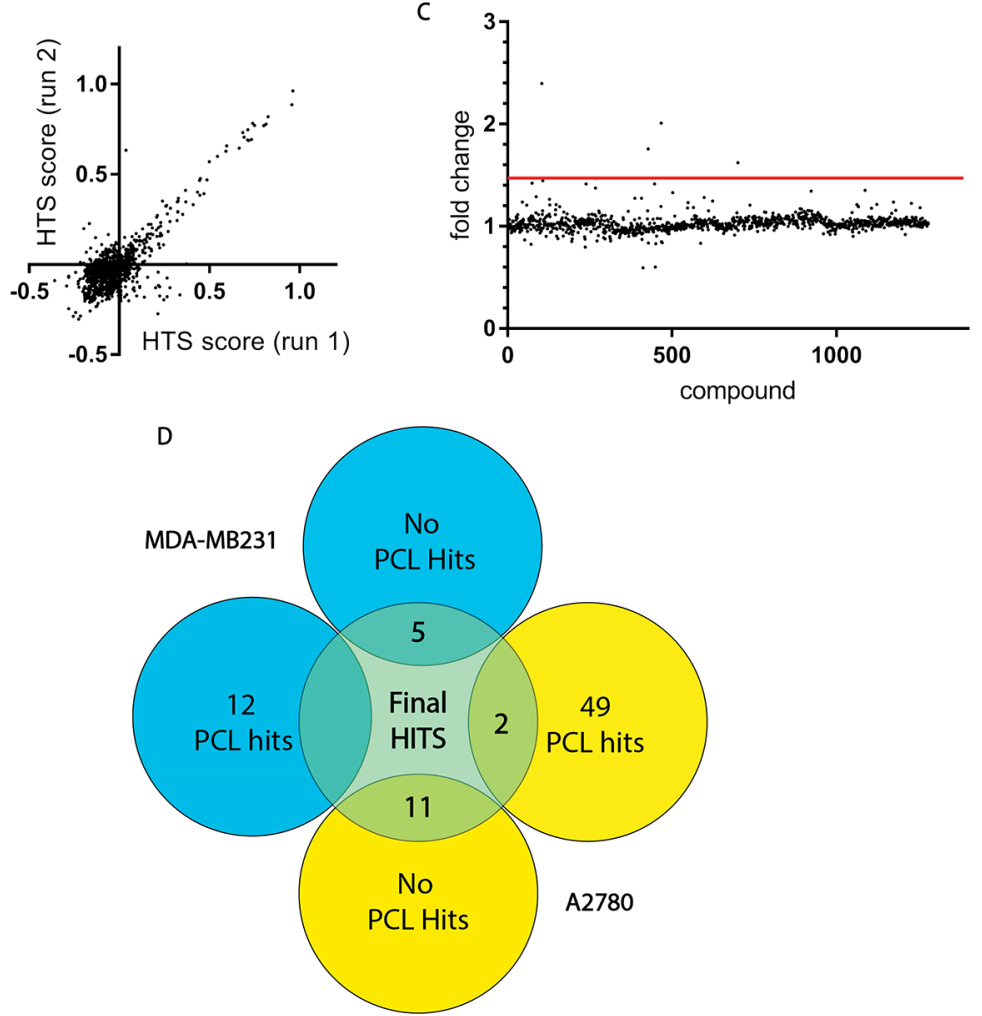

Figure 1. The Prestwick Chemical Library screen with human breast adenocarcinoma MDA-MB231 cells and human ovarian A2780 carcinoma cells. (A) Schematic representation of the screening assay design. (B) Representative scatter plot of the PCL screen performed in duplicate (run 1 vs run 2) against A2780 cells. The results of two parallel runs are plotted against each other and show the reproducibility of the screen. Fluorescent intensity of each compound was normalized to the corresponding controls on every plate and presented as HTS scores, where a score of 0 corresponds to the average fluorescence intensity of the negative control wells (and denotes "no cytotoxic activity") and a score of 1 to that of the positive control wells $\left(10 \mu \mathrm{M} \mathrm{CuSO}_{4}\right)$, indicating "very active compounds". Out of 1280 compounds, 51 compounds were identified as PCL hits with an HTS score $>0.2$ against human ovarian A2780 carcinoma cells and 12 drugs were found to be effective against MDA-MB-231 cells. (C) Representative screening data of 1280 compounds tested against MDA-MB231 cells. The scatterplot shows the fold change in HTS score of PCL drug-treated wells relative to the drug/RAPTA-T combination-treated wells for 1280 compounds. Five compounds showed a 1.5 fold increased inhibition of cell growth upon RAPTA-T treatment and were identified as final hits. (D) Scheme summarizing the results from two parallel screens, in the absence (PCL hits) and presence of RAPTA-T, each performed in duplicate. The final hits were identified based on a 1.5 fold increased HTS score for compounds in combination with RAPTA-T compared to single drug treatment. The pool of final hits consisted of 18 compounds (Table S1).

procedures were carried out in accordance with the approved guidelines.

Tumor Implantation, Treatment, Growth Measurement. A total of $1 \times 10^{6}$ tumor cells in $100 \mu \mathrm{L}$ of PBS were injected s.c. into the shaved flank of 7 week-old C57BL/ 6 mice. At days 5, 7, 9, 12, 14, and 16 progressing tumors were injected with $100 \mu \mathrm{L}$ of PBS solution containing varying doses of RAPTA-T $(125,250,500,1250 \mu \mathrm{g})$ or haloprogin (36 ng, 360 $\mathrm{ng}, 3.6 \mathrm{mg}$ ) or the combination of $250 \mu \mathrm{g}$ RAPTA-T and $36 \mathrm{ng}$ haloprogin. cGAMP (10 $\mu \mathrm{g}$ per tumor) was injected as positive control. The total number of immune cells upon RAPTA-T treatment was not significantly increased compared to PBS control treatment. The tumor volume was measured with a digital caliper every other day and calculated using the modified ellipsoid formula $V=\left(L \times l^{2}\right) / 2$, where $L$ is the widest and $l$ the smallest diameter. Drug treatment effect on tumor growth rate was assessed by determining $\% T / C_{\text {day } x}$ calculated by [(mean tumor volume of treated group on day $X /$ mean tumor volume of control vehicle group on day $X) \times 100]$. Potentiation of RAPTA-T efficacy was assessed by comparing the tumor growth inhibition effect in the RAPTA-T monotherapy group $\left(C_{\mathrm{RT}}\right)$ to the tumor growth inhibition effect by the RAPTA-T/ haloprogin combination group $\left(T_{\mathrm{RT}+\mathrm{H}}\right)$ on day $X$ calculated by [mean tumor volume of $\left.T_{\mathrm{RT}+\mathrm{H}} / C_{\mathrm{RT}} \times 100\right]$. At the end of the 
experiment, tumors were harvested, embedded in OCT for histology, or processed to generate a single cell suspension for flow cytometry analysis.

Generation and Analysis of Tumor Cell Suspensions by Flow Cytometry Analysis. Tumors were harvested, rinsed with PBS, and passed through a $70 \mu \mathrm{m}$ cell strainer to obtain a single cell suspension. Cells were stained with antibodies against CD45 (30F11), CD3 (145.2C11), CD8a (53-6.7), and CD4 (RM4-5) purchased from BD Pharmingen or eBioscience. Data were acquired on a FACS Calibur (Becton Dickinson), and analyzed with Flow-Jo V10 software.

Histology and Immunofluorescence. For histopathological evaluation, $8 \mu \mathrm{m}$ sections were cut with a cryostat, thawed and mounted on Superfrost plus (Thermo Scientific) slides, air-dried, and stored at $-20{ }^{\circ} \mathrm{C}$ until further use. For histology, tissue sections were stained with hematoxylin and eosin. For immunohistochemistry, tissue sections were fixed with $\mathrm{MeOH}$ for $10 \mathrm{~min}$ at $-20{ }^{\circ} \mathrm{C}$, stained with anti-CD45 (MCD-4500, Life Technologies, clone 30-F11) primary antibody (1:200), followed by donkey antirat biotinylated secondary antibody (1:200), followed by alkaline phosphatasestreptavidin (1:200) and Fast Red chromogen. Prior to immunohistochemistry for cleaved caspase-3, tumor tissue sections were fixed in 4\% PFA for $10 \mathrm{~min}$ at rt. After washing in PBS, the sections were permeabilized with $0.25 \%$ Triton X-100 for 10 min, washed with PBS and blocked with $1 \%$ BSA. Then the sections were incubated with the rabbit anticleaved caspase3 (Asp 175) antibody (1:200, \#9661, Cell Signaling, Beverly, MA) overnight at $4{ }^{\circ} \mathrm{C}$. The donkey antirabbit Alexa568 (1:1000) secondary antibody was applied to locate the primary antibody. Nuclear staining was performed with DAPI. Image acquisition was performed using the Olympus Slide Scanner VS120-L100.

Image Analysis and Quantification. Images were processed with Fiji. A threshold for each channel of interest (COI, e.g. cleavedCasp3, DAPI) was set by autothreshold (method: Default, Dark) and binary images were created from which the number of stained objects and total number of nuclei were determined by manual point counting. Eight random fields per sample were selected and counted for all indices.

RNA Isolation and Gene Expression. Tumors were homogenized in TRIzol (Invitrogen) and RNA was isolated with chloroform and further isopropanol precipitation. The concentration and purity of the RNA solution were determined by using a NanoDrop spectrophotometer (ThermoFisher Scientific). cDNA was obtained from 1 to $2 \mu \mathrm{g}$ of total RNA using SuperScript II reverse transcriptase (Invitrogen) according to the manufacturer's protocol. mRNA expression levels for cytokines were analyzed using specific Taqman probes (Life Technologies) and Taqman gene expression master mix (Life Technologies). Amplifications were performed using the Step One Real-Time PCR system (Applied Biosystem). The $\Delta \mathrm{Ct}$ was used for statistical analysis, and the treated group values were presented as fold of control mean value.

Statistical Analysis. All statistical analyses were performed with GraphPad Prism 7.02 software. Test, group sizes, and $P$ values are given in the corresponding figure legends. $P$ values $<0.05$ were considered statistically significant.

\section{RESULTS}

Prestwick Library Screen. The Prestwick Chemical Library (PCL) used in this screen is composed of 1280 offpatent, approved, small molecule drugs of wide pharmaco- logical diversity. We screened these drugs against the human breast adenocarcinoma MDA-MB231 and the human ovarian A2780 carcinoma cancer cell lines as single drugs and in combination with RAPTA-T using the PrestoBlue cell viability assay to identify drugs that are more cytotoxic in the presence of RAPTA-T than as single agent. Parallel screens were performed in the presence and absence of RAPTA-T (Figure 1A). The concentration of RAPTA-T used in the screen was determined by a prior titration with RAPTA-T on several cancer cell lines. A concentration of $50 \mu \mathrm{M}$ was chosen because RAPTA-T has no cytotoxic effect on cell growth at that concentration (Figure S1). From the primary screen of the entire PCL at a fixed concentration of $10 \mu \mathrm{M}$, in the absence of RAPTA-T and with a short incubation time of $24 \mathrm{~h}, 51$ drugs were found to be active against human ovarian A2780 carcinoma cells and 12 drugs were active against human breast adenocarcinoma MDA-MB231 cells (named as PCL hits). The reproducibility of two parallel screens is shown in Figure 1B. Compounds were identified and statistically validated as hits when their average HTS scores were 1.5 times higher in the presence of RAPTA-T than the respective average HTS scores without RAPTA-T (Figure 1C). Five compounds (parthenolide, mitoxantrone, chrysene-1,4-quinone, daunorubicin, and haloprogin) from the screen against MDA-MB231 were identified as final hits when screened in the presence of RAPTA-T, but which did not give a PCL hit when screened as single agent only. The screen on A2780 cells gave 51 PCL hits, out of which two compounds (isoetharine and primaquin) were identified as final hits with a higher HTS score in the presence of RAPTA-T. Eleven additional compounds, which were not PCL hits as single agent, were identified as final hits in the presence of RAPTA-T (Figure 1D). The pool of final hits from two separate screens performed on two cancer cell lines comprised a total of 18 compounds. A list summarizing the hit results with HTS score values and their pharmacological classification is given in the Supporting Information (Table S2). Interestingly, final hits detected in the MDA-MB231 cell screen, were not found as hits in the A2780 cell screen and, the final hits of the A2780 cell screen did not lead to hits in MDAMB231 cells. Surprisingly, out of 18 hit compounds only two compounds (mitoxantrone and daunorubicin) are chemotherapeutic agents. The other compounds may be classified as anti-inflammatory, antiparasitic, or as adrenergic inhibitors, with the majority of compounds assigned to the last class.

RAPTA-T Potentiates Cell Killing by Haloprogin. We selected two compounds, parthenolide and haloprogin, out of the HTS hit pool with interesting properties as repurposing candidates, since they are drugs that are not already considered chemotherapeutic drugs, but showed increased anticancer activity in the presence of RAPTA-T. Parthenolide, a naturally occurring sesquiterpene lactone of nucleophilic nature, allows rapid interactions with biological sites. Its anticancer and proapoptotic characteristics, through i.a. selective induction of ROS in cancer cells have already been demonstrated. ${ }^{26-30}$ Haloprogin is a synthetic antifungal agent, administered topically for dermatophytic infections. ${ }^{31,32}$ Its mechanism of action is unknown, but it is believed to act through disruption of the cytoplasmic membrane structure and function thereby enhancing membrane permeability. It is therefore used only topically.

The activity of the two drugs was confirmed in doseresponse experiments against MDA-MB-231 and A2780 in combination with RAPTA-T (Figure S3). Both compounds 
A

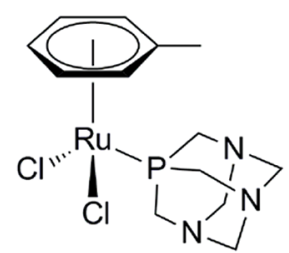<smiles>Clc1cc(Cl)c(OCC#CI)cc1Cl</smiles>
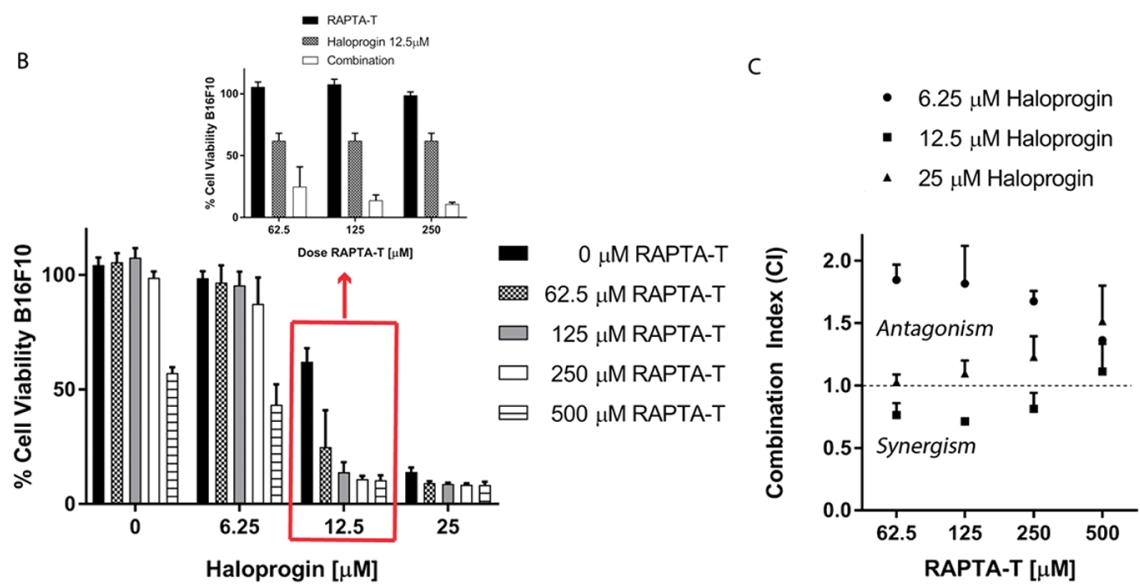

Figure 2. RAPTA-T and haloprogin synergistically inhibit melanoma B16F10 cell viability. (A) Chemical structures of RAPTA-T (left) and haloprogin (right). (B) Cells were treated with haloprogin $(6.25-25 \mu \mathrm{M})$ alone and in combination with RAPTA-T $(62.5-500 \mu \mathrm{M})$ for $72 \mathrm{~h}$ and cytotoxicity determined by the Presto Blue assay after $72 \mathrm{~h}$. The bar graphs depict drug-response relationships for the sensitization effect of RAPTA$\mathrm{T}$ on the cytotoxicity of haloprogin, with the strongest effect obtained with $12.5 \mu \mathrm{M}$ haloprogin and low doses of RAPTA-T (shown in small bar graph). (C) Combination indices as a function of RAPTA-T concentration. Values $<0.9$ indicate synergy, values $>1.2$ antagonism, values $0.9<\mathrm{CI}<$ 1.2 indicate an additive effect.

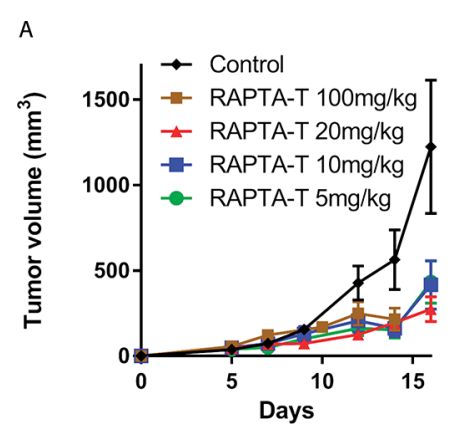

B

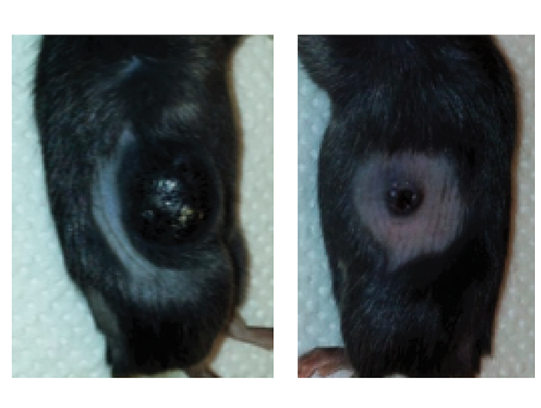

Figure 3. RAPTA-T in monotherapy elicits antitumor activity against established subcutaneous murine B16F10 melanoma in C57BL/6 immunocompetent mice. (A) When the tumor reached a volume of $50-100 \mathrm{~mm}^{3}$, animals $(N=5$ per group in each experiment) received five intratumoral injections of either $1.25 \mathrm{mg}, 250 \mu \mathrm{g}, 125 \mu \mathrm{g}$ or $62 \mu \mathrm{g}$ of RAPTA-T at days 5, 7, 9, 12, and 14. The data are pooled from 3 independent experiments. (B) Tumors on day 19 after (a) PBS and (b) $20 \mathrm{mgkg}^{-1}$ RAPTA-T treatment. Phosphate-buffered saline (PBS) was used as a control vehicle. Data represent mean tumor volumes \pm SEM.

showed dose-dependent cytotoxic activity in both cell lines of similar potency with $\mathrm{IC}_{50}$ values in the low micromolar range (4-12 $\mu \mathrm{M}, 72 \mathrm{~h}$ drug exposure). Synergistic activities of both compounds in combination with RAPTA-T were observed only in MDA-MB231 cells, whereas in A2780 cells additive or even antagonistic effects predominated (Figure S4). This is in accordance with the performed HTS screen, where both drugs were identified as hits with the highly aggressive and invasive cell line, MDA-MB231, but not with A2780 cells.

The property of haloprogin to enhance membrane permeability caught our attention and triggered further investigation of this molecule in combination with RAPTA-T. We were intrigued by the possibility to test haloprogin on melanoma since, for the prospect of its development as anticancer drug, it could potentially be applied as its clinically approved topical dosage form, as ointment or cream, directly on the tumor site. For this reason, we chose the highly proliferating $\mathrm{B} 16 \mathrm{~F} 10$ melanoma cell line with the prospect to perform further testing of the Haloprogin/RAPTA-T-combination on a syngeneic orthotopic melanoma mouse model known for its aggressive behavior.

The synergistic effect of the RAPTA-T/haloprogin combination (for chemical structures see Figure 2A) shown before in ovarian A2780 and breast MD-MB231 cancer cell lines, was validated on murine B16F10 melanoma cells. Cells were incubated with haloprogin (doses ranging from 6.25 to $25 \mu \mathrm{M}$ ) combined with RAPTA-T $(62.5-500 \mu \mathrm{M})$ and the cell viability was measured after a drug exposure of $72 \mathrm{~h}$ using the PrestoBlue cell viability assay. The strongest synergistic effect was obtained with $12.5 \mu \mathrm{M}$ haloprogin (the approximate $\mathrm{IC}_{50^{-}}$ $72 \mathrm{~h}$ concentration) combined with low dose 62.5 or $125 \mu \mathrm{M}$ RAPTA-T (Figure 2B). The calculated combination indices, 
Table 1. Efficacy of RAPTA-T and Haloprogin Monotherapy and Combination Therapy in the B16F10 Murine Melanoma Flank Tumor Model ${ }^{a}$

\begin{tabular}{|c|c|c|c|c|c|c|}
\hline $\begin{array}{l}\text { compound } \\
(\mathrm{mg} / \mathrm{kg} / \text { day })\end{array}$ & $\begin{array}{l}\text { mean tumor volume } \\
\left(\mathrm{mm}^{3} \pm \mathrm{SEM}\right)\end{array}$ & $\% \mathrm{~T} / \mathrm{C}_{\mathrm{veh}}(\% \mathrm{TGI})$ & ANOVA/Tukey & $\begin{array}{l}\text { mean tumor volume } \\
\left(\mathrm{mm}^{3} \pm \mathrm{SEM}\right)\end{array}$ & $\% \mathrm{~T} / \mathrm{C}_{\mathrm{veh}}(\% \mathrm{TGI})$ & ANOVA/Tukey \\
\hline study A & & day 16 & & & & \\
\hline \multicolumn{7}{|l|}{ RAPTA-T } \\
\hline 100 , i.t & N/A & & & & & \\
\hline 20 , i.t & $274 \pm 73$ & $22(78)$ & 0.02 & N/A & N/A & N/A \\
\hline 10 , i.t & $416 \pm 141$ & $34(66)$ & ns & & & \\
\hline 5, i.t & $433 \pm 123$ & $35(65)$ & $\mathrm{ns}$ & & & \\
\hline \multicolumn{7}{|l|}{ haloprogin $^{b}$} \\
\hline 0.144 , i.t & $931 \pm 228$ & $91(9)$ & ns & N/A & N/A & N/A \\
\hline 0.014 , i.t & $804 \pm 133$ & $79(21)$ & ns & & & \\
\hline $1.44 \times 10^{-3}$, i.t & $604 \pm 224$ & $59(41)$ & $\mathrm{ns}$ & & & \\
\hline study B & & day 16 & & & day 19 & \\
\hline \multicolumn{7}{|l|}{ RAPTA-T } \\
\hline $\begin{array}{l}\text { 20, i.t } \\
\text { haloprogin }\end{array}$ & $274 \pm 73$ & & 0.02 & $447 \pm 139$ & $35(65)$ & 0.008 \\
\hline $\begin{array}{l}1.44 \times 10^{-3} \text {, i.t } \\
\text { RAPTAT/haloprogir }\end{array}$ & $574 \pm 110$ & $82(18)$ & 0.77 & $1327 \pm 230$ & $100(0)$ & 0.9 \\
\hline $20 / 1.44 \times 10^{-3}$, i.t & $157 \pm 39$ & $22(78)$ & 0.001 & $223 \pm 59$ & $17(83)$ & 0.001 \\
\hline
\end{tabular}

which were $0.76 \pm 0.09$ (for $12.5 \mu \mathrm{M}$ haloprogin combined with $62.5 \mu \mathrm{M}$ RAPTA-T) and $0.71 \pm 0.02$ for $12.5 \mu \mathrm{M}$ haloprogin combined with $125 \mu \mathrm{M}$ RAPTA-T) confirmed a synergistic drug interaction in B16F10 melanoma cells (Figure $2 \mathrm{C})$. The computed degree of synergism of the drug combination can be described as "moderate synergism" according to Chou. ${ }^{33}$ Notably, for certain mutual drug concentrations the calculated combination index relates to antagonism, which indicates that exact concentrations of the individual drugs might be critical when used in combination for cancer treatment.

RAPTA-T Inhibits B16F10 Melanoma Tumor Progression in Vivo. First, the efficacy of RAPTA-T was tested in vivo in the syngeneic B16F10 mouse melanoma model, a wellestablished and widely used tumor model for which treatment is notoriously difficult. ${ }^{34,35}$ Starting 5 days after tumor cell inoculation, when palpable tumors of $4-5 \mathrm{~mm}$ in diameter developed, mice were treated on alternate days by intratumoral injections of RAPTA-T at different concentrations (100, 20, 10, and $5 \mathrm{mgkg}^{-1}$ body weight) for a total of 6 treatments (Figure 3A). A high dose of $100 \mathrm{mgkg}^{-1}$ RAPTA-T turned out to be toxic to the animals, however, reducing the concentration by a factor of 5-20 led to equally high antitumor responses without any signs of toxicity (e.g., overt signs of significant weight loss, dehydration, lack of grooming). The tumor volume was reduced by $>60 \%$ in all three groups treated with RAPTA-T (5, 10, and $20 \mathrm{mgkg}^{-1}$ body weight) compared to control tumors treated with PBS vehicle (Table 1). During the course of three independent experiments, RAPTA-T demonstrated robust, consistent efficacy in the B16F10 melanoma model.

Melanoma tissues of RAPTA-T treated tumors were analyzed by histological examination to further investigate whether tumor growth inhibition was induced by direct cytotoxicity of RAPTA-T on tumor cells in vivo. We assessed possible morphological changes in cell density, nuclei alteration and cell death signals. The control group showed characteristics such as large blood vessels, nuclear hyperchromasia, multinucleation, and proliferating cell clusters, which are associated with intense proliferative activity and conventional criteria for malignancy. The RAPTA-T group showed pyknotic nuclei, decreased nuclei/cytoplasmic ratio and nuclear degradation, which are clear signals of cell death, mainly by apoptosis (Figure 4). These characteristics were enhanced at the tumor periphery. Necrotic areas in tumor tissue were not detected. To further investigate the role of apoptosis, tumor sections were stained for expression of cleaved caspase-3. RAPTA-T induced caspase3 expression in tumors was significantly $(P<0.05)$ different compared to control tumors (Figure 4C). RAPTA-T treatment showed 2.3-fold increased expression of cleaved caspase-3 in tumors tissues compared to the control group (Figure 4D). The observation that RAPTA-T induces apoptotic cell death in vivo in the B16F10 melanoma model is particularly surprising since in previous experiments RAPTA-T showed an apoptosisindependent cell death mechanism.

Therapeutic Efficacy of RAPTA-T Is Not Mediated by an Anticancer Immune Response. We sought to evaluate whether RAPTA-T recruits T-cells to cutaneous tumors and, hence, is able to induce a localized inflammatory response that could trigger anticancer immunity. We first assessed the global presence of immune cells by immunohistochemistry on tissue sections of tumors treated with RAPTA-T $\left(5\right.$ or $\left.10 \mathrm{mgkg}^{-1}\right)$ or PBS as a control vehicle using the pan-leukocyte marker CD45. Tissue sections of tumor treated with cyclic dinucleotide GMPAMP (cGAMP) served as a positive control. ${ }^{36}$ We observed by immunohistochemical analysis of the border region between tumor mass and healthy tissue a higher density of CD45+ leukocytes in some tissue sections of RAPTA-T treated tumors (Figure 5A). However, the total number of immune cells upon RAPTA-T treatment was not significantly increased compared to PBS control treatment (Figure 5B). By quantitatively assessing CD4+ and CD8+ T cell infiltration by flow cytometry, we found no significant differences in the content of any $\mathrm{T}$ lymphocyte type between RAPTA-T treated and PBS control tumors (Figure 5C and D). Similar results were obtained for 

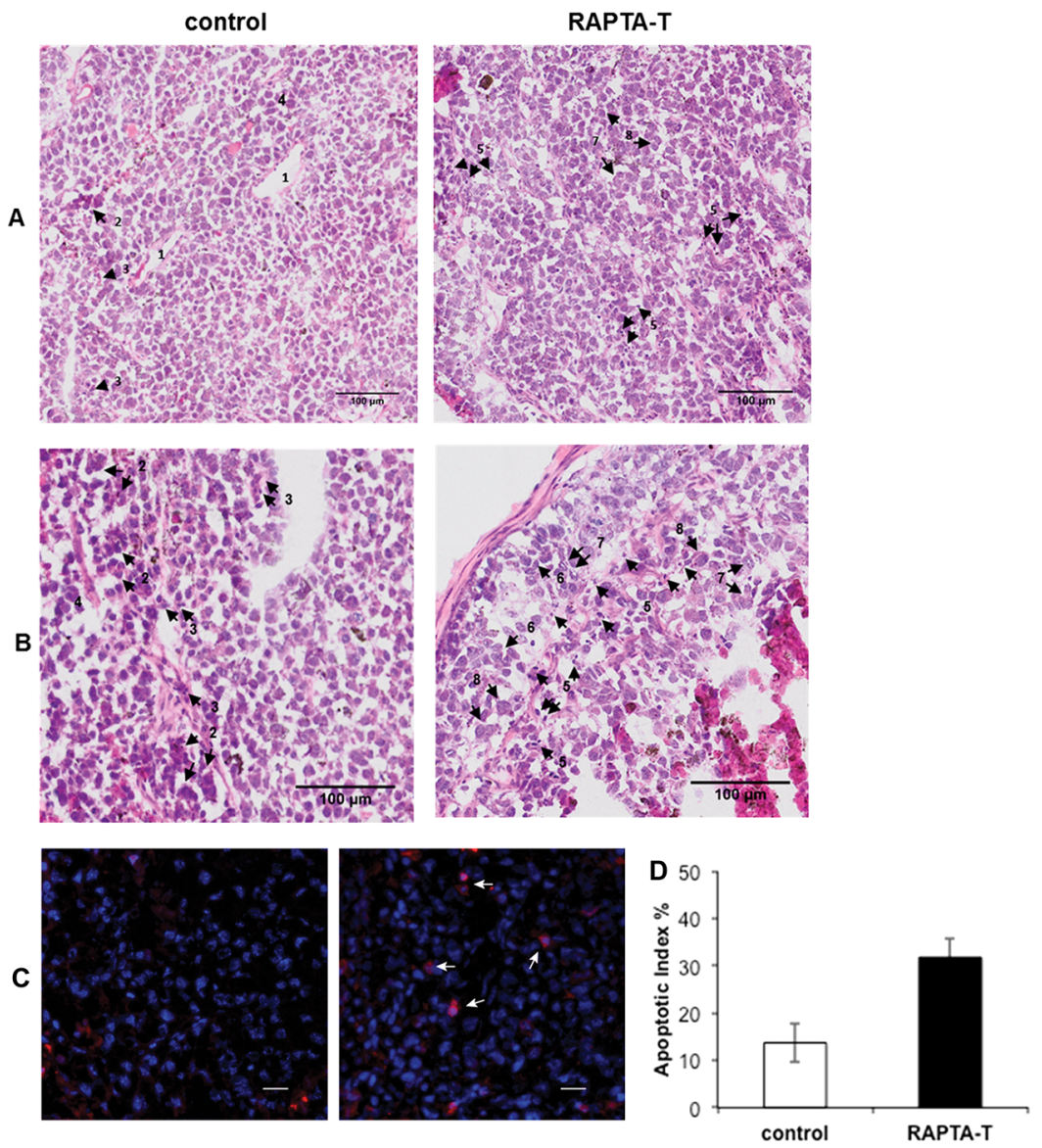

Figure 4. RAPTA-T induces apoptosis in B16F10 melanoma of C57BL/6 mice. (A) The control group shows characteristics, such as (1) large blood vessels, (2) proliferating cell cluster, (3) multinucleation, and (4) nuclear hyperchromasia. The RAPTA-T group (right panels) exhibit (5) pyknotic nuclei, (6) a decreased nuclei/cytoplasmic ratio and (7) nuclear degradation, and (8) karyomegaly (enlarged cell nuclei). These characteristics are enhanced at the tumor periphery (B); magnification: $\times 20$. (C) Immunostaining of cleaved caspase 3 (red) as a measure of apoptotic cells death indicate a higher apoptotic activity in tumors treated with RAPTA-T (right) compared to control (left). Nuclei have been stained with DAPI (blue). Scale bar: $20 \mu \mathrm{m}$. (D) The apoptotic index as a measure of cleaved caspase 3 on tumor sections is significantly higher in RAPTA-T treated tumors $(P$ $=0.036)$.

the change of expression levels of inflammatory cytokines. IL1 $\beta$, $\operatorname{IFN} \gamma, \mathrm{TNF} \alpha$, and IL12a were equally represented in treated and PBS control tumors. An up-regulated expression of these cytokines was not observed (Figure 5E). Based on these results, we excluded an inflammatory response triggered by RAPTA-T.

Haloprogin Administered in Combination with RAPTA-T Increases Inhibition of Melanoma Growth. We tested the efficacy of haloprogin monotherapy at different concentrations (1,10, and $100 \mu \mathrm{M}$ corresponding to $1.4,14.4$, and $144 \mu \mathrm{gkg}^{-1}$ body weight) on B16F10 tumor growth. Cells were inoculated on both flanks of mice. Established tumors on both flanks were treated by four intratumoral injections every other day (on days 5, 7, 10, and 12). Since haloprogin is waterinsoluble, a stock solution was prepared in $100 \% \mathrm{EtOH}$ and serially diluted to the final concentration in PBS, with EtOH not exceeding $1 \%(\mathrm{v} / \mathrm{v})$. The intratumoral injection of haloprogin led to an inverse drug-response behavior on tumor growth (Table 1). High doses (10 and $100 \mu \mathrm{M})$ of haloprogin did not show any significant tumor growth inhibition compared to control injections with $1 \% \mathrm{EtOH}$, whereas a low dose $(1 \mu \mathrm{M})$ significantly inhibited tumor growth in three out of four mice ( $P=0.0003$, 2-way ANOVA). Only one out of 8 tumors did not respond to the treatment (Figure 6A).
To study the potential of the combination RAPTA-T/ haloprogin treatment, mice with one tumor on each flank $(N=$ 5 per group, 10 tumors) were treated over 2 weeks with a total of six intratumoral injections of either monotherapy RAPTA-T $(250 \mu \mathrm{g})$, monotherapy haloprogin $(1 \mu \mathrm{M})$ or the combination thereof. Tumors on both flanks were treated the same way. Nine out of ten tumors treated with the RAPTA-T/haloprogin combination showed significantly lower tumor growth compared to RAPTA-T treatment alone $(P<0.001,2$-way ANOVA, Figure 6B). One tumor within this group did not respond to the combination treatment. Haloprogin produced a significant potentiation by $50 \%$ of RAPTA-T efficacy at day 19 compared to RAPTA-T monotherapy.

\section{DISCUSSION}

With the goal to investigate good drug combinations and ideally, at the same time, identify potential novel anticancer agents by making use of existing resources, we used an in vitro high throughput screen (HTS) with a library of clinically approved drugs ${ }^{37,23}$ that interact with the experimental ruthenium drug RAPTA-T to induce cancer cell killing. We could narrow the pool from 1280 approved drugs to 18 hit compounds that led to enhanced activity when used in combination in highly invasive human breast or ovarian cancer 


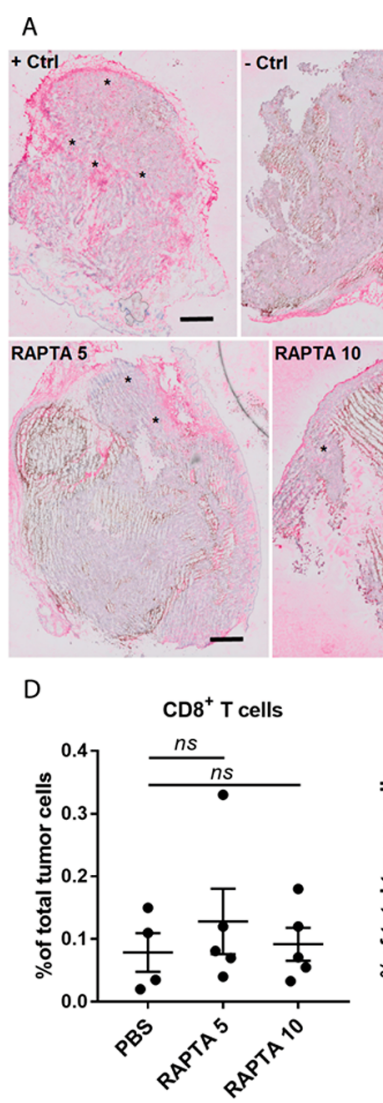

\section{B}

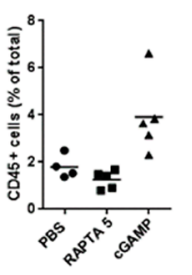

$-$

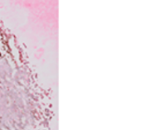

(1)

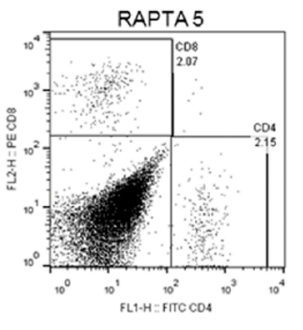

C + control
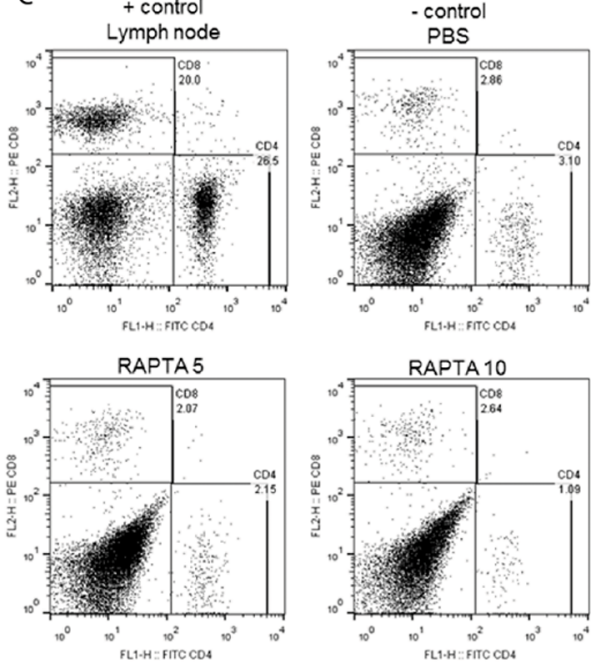

$\mathrm{E}$
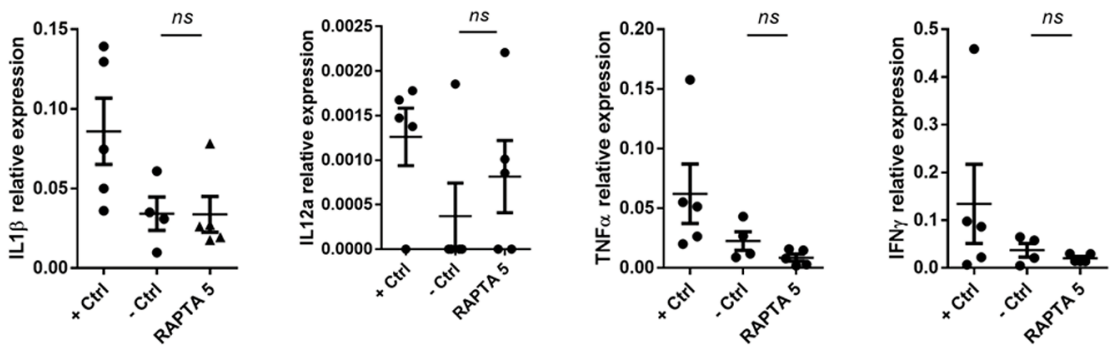

Figure 5. RAPTA-T does not recruit $T$ lymphocytes to tumors. (A) Immunohistochemistry of CD45+ lymphocytes inside the B16F10 tumor mass, marked by an asterisk, and in the peritumoral area, in + control (cGAMP), - control (PBS), and RAPTA-T treated groups $\left(10\right.$ and $\left.5 \mathrm{mgkg}{ }^{-1}\right)$. Scale bar: $100 \mu \mathrm{m}$. (B) Quantification of the number of CD45+ cells in tumor tissue. (C) Flow cytometry dot plots of CD8+ and CD4+ T cells infiltrating tumors. (D) Quantification of the number of CD8+ and CD4+ T lymphocytes. Data are expressed as \% cells of total tumor cells and represented as mean \pm SEM with $N=4-5$ (ns, not significant by unpaired $t$ test). (E) Cytokine induction in response to intratumoral administration of RAPAT-T $\left(62.5 \mu \mathrm{g}, 5 \mathrm{mgkg}^{-1}\right)$, PBS (-Ctrl) or cGAMP (+ Ctrl) at days 5, 7, 9, 12, and 14. Tumors were harvested at day 16 for RNA extraction. Analysis of $\operatorname{IL} 1 \beta, \operatorname{TNF} \alpha$, IFN $\gamma$, and IL12a gene expression was performed by quantitative PCR. ns, not significant by unpaired $t$ test.

cells. Among these drugs we found not only anticancer drugs, but also other interesting drug classes including antiinflammatory and antiparasitic drugs and adrenergic inhibitors. From this screen, we discovered a potent interaction between haloprogin, an antifungal agent, and RAPTA-T. These two small-molecule compounds, when combined, led to synergistic activity in several cancer cell lines and showed an improved therapeutic response on tumor growth over either agent alone for cutaneous melanoma of mice.

Problems, such as chemo-resistance and systemic toxicity with chemotherapeutic drugs are most often encountered with melanoma. Alkylating agents in clinical use, such as dacarbazine and temozolomide, comprise a unique family of cytotoxic drugs that have demonstrated some efficacy in melanoma patients, however being only effective in around $10-20 \%$ of cases having received monotherapy. The cytotoxicity of these drugs is attributed to the induced $\mathrm{O}^{6}$-methylguanine lesion. ${ }^{38}$ In this respect, RAPTA-T with the ability to target other biomolecules than DNA, ${ }^{16}$ could provide a possible alternative to conventional chemotherapeutics in melanoma treatment. In addition, the remarkably low general toxicity of RAPTA compounds and haloprogin attributed to fast clearance from the organs and the bloodstream through excretion by the kidneys make the two compounds a promising combination for translation to clinical evaluation. ${ }^{15,39,40}$

Remarkably, in our study, RAPTA-T even as monotherapy at substantially lower concentrations elicited a very similar or even greater antitumor response in the same mouse model compared to the standard chemotherapeutic drugs dacarbazine and temozolomide administered as single treatments. ${ }^{41-43}$ In combination with haloprogin, the efficacy of RAPTA-T was significantly potentiated by $50 \%$ compared to RAPTA-T 

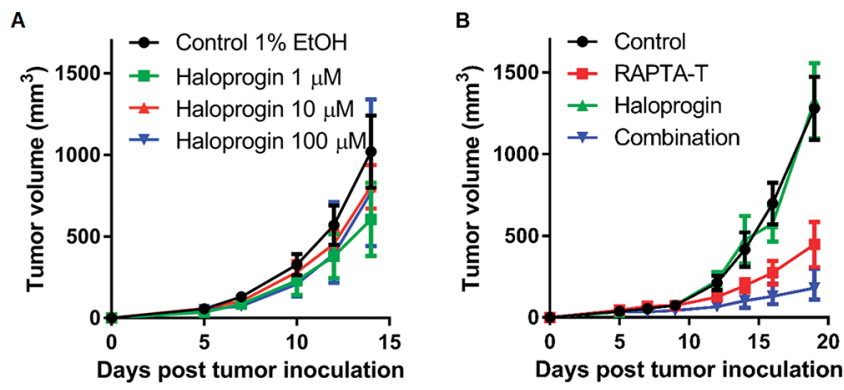

Figure 6. Chemotherapy with haloprogin and RAPTA-T controls B16F10 tumor growth. (A) Haloprogin in monotherapy at 1,10 , and $100 \mu \mathrm{M}$ given at days $5,7,10$, and 12 administered intratumorally. B16F10 tumor cells were inoculated on both flanks of mice $(N=4$ per group, 8 tumors). Tumors on each flank were treated the same way. $1 \% \mathrm{EtOH}$ in PBS was given as control vehicle. Low dose Haloprogin significantly inhibited tumor growth compared to control tumors $(P<$ 0.001, 2-way ANOVA). (B) Mice ( $N=5$ per group, 10 tumors) received six intratumoral injections in both tumors of either RAPTA-T alone $(250 \mu \mathrm{g})$, haloprogin alone $(1 \mu \mathrm{M})$, or the combination thereof. PBS was used as control vehicle. Nine out of ten tumors treated with the RAPTA-T/Haloprogin combination showed significantly lower tumor growth compared to RAPTA-T treatment alone $(P<0.001,2$ way ANOVA). One tumor did not respond to the combination treatment.

monotherapy. The efficacy of the drug combination treatment therefore is greatly enhanced compared to the standard agents for melanoma treatment, dacarbazine, and temozolomide, used in clinic.

Although anticancer drugs act mostly by direct induction of apoptosis in cancer cells, many drugs may also promote immunogenic cell death, which stimulates the antitumor immune response and contributes to the therapeutic efficacy. ${ }^{44-47}$ Chemotherapeutics may also induce stress signals leading to increased susceptibility of cancer cells to immune attack or have the potential to reengineer the overall host milieu and the local tumor microenvironment to disrupt immune tolerance and suppression pathways. ${ }^{48}$ In melanoma, mixed responses to chemotherapy are frequently observed. ${ }^{49}$ Various groups have shown in both preclinical models and in cancer patients that several drugs can abrogate the suppressive influence of regulatory $\mathrm{T}$ cells allowing effective antitumor immunity to emerge. Immunological effector cells such as CD3+ T-cells, CD45+ T-cells and macrophages reduce tumor progression when infiltrated into cancer tissue. ${ }^{50}$

Among anticancer drugs, oxaliplatin and the ruthenium compound NAMI-A are the only metal-based compounds for which immunomodulatory effects have been reported; NAMI-A was shown to induce lymphocytes to infiltrate the tumor mass, ${ }^{51}$ whereas oxaliplatin causes expression of immunogenic signals on cancer cells prior to apoptosis, which in turn activates the innate immune system and results in IFN $\gamma$ production and interaction with TLR4 of dendritic cells thereby creating a tumor vaccine. ${ }^{52,53}$ Our results show that the tumor regression induced by RAPTA-T, when administered intratumorally, is unlikely to be mediated by tumor infiltrating $\mathrm{T}$ cells. Also immune system activation through recruitment of macrophages or dendritic cells may not play a role since the release of cytokines, such as IL1 $\beta, \operatorname{TNF} \alpha, \operatorname{IFN} \gamma$, and IL12a, was not significantly increased in RAPTA-T treated tumors. Histological examination of tumor sections rather suggests a direct cytotoxic effect of RAPTA-T on B16F10 tumor cells.
In order to develop this combination treatment strategy as cancer therapeutics further, a complete dose-effect study in vivo with varying concentrations of both drugs should be performed to exclude possible antagonistic effects seen in vitro. In addition, it needs to be determined whether current combination strategy with demonstrated efficacy against local tumors, would also efficiently prevent metastatic melanoma, the main challenge for present and future systemic therapies. In this respect, RAPTA-T with demonstrated antimetastatic potential in reducing the number of metastases in lungs of mice with mammary carcinoma might be worth to explore. ${ }^{15}$ For both drugs, different administration routes should be further investigated since the current combination treatment strategy with topical or intratumoral administration might only be limited to treatment of local tumors.

In summary, our data suggest a strategy of inducing cancer cell death with RAPTA-T as possible alternative to highly cytotoxic chemotherapeutic agents in established melanoma where classical chemotherapeutics have failed to be very much effective. Moreover, RAPTA-T proved to be a striking candidate for its use in combination treatment with haloprogin, in which the repurposed drug can be administered in very low concentrations to potentiate RAPTA-T efficacy and efficiently inhibit melanoma growth. Whether such treatment might be also efficient against inhibiting metastatic spread and treating metastases of melanoma has to be addressed in the future.

\section{ASSOCIATED CONTENT}

\section{S Supporting Information}

The Supporting Information is available free of charge on the ACS Publications website at DOI: 10.1021/acs.molpharmaceut. 7 b00764.

Hits identified from the Prestwick Chemical Library, dose-response curves for RAPTA-T, and the drug combinations and determination of combination indices (PDF)

\section{AUTHOR INFORMATION}

\section{Corresponding Authors}

*Tel: +41 (0)21 31403 60; Fax: +41 (0)21 3140382 l; Email: michel.gilliet@chuv.ch.

*Tel: +41 (0)21 69398 54; Fax: +41 (0)21 69397 80; E-mail: paul.dyson@epfl.ch.

ORCID $\odot$

Paul J. Dyson: 0000-0003-3117-3249

\section{Notes}

The authors declare no competing financial interest.

\section{ACKNOWLEDGMENTS}

We thank the Swiss National Center for Competence (NCCR) in Chemical Biology for providing access to the chemical libraries and screening facilities and are grateful to the Biomolecular Screening Facility and the Histology Core Facility at the EPFL for their expert technical support.

\section{REFERENCES}

(1) Chabner, B. A.; Roberts, T. G. Timeline: Chemotherapy and the War on Cancer. Nat. Rev. Cancer 2005, 5 (1), 65-72.

(2) Cheung-Ong, K.; Giaever, G.; Nislow, C. DNA-Damaging Agents in Cancer Chemotherapy: Serendipity and Chemical Biology. Chem. Biol. 2013, 20 (5), 648-659. 
(3) Remesh, A. Toxicities of Anticancer Drugs and Its Management. Int. J. Basic Clin. Pharmacol. 2012, 1 (1), 2.

(4) Masui, K.; Gini, B.; Wykosky, J.; Zanca, C.; Mischel, P. S.; Furnari, F. B.; Cavenee, W. K. A Tale of Two Approaches: Complementary Mechanisms of Cytotoxic and Targeted Therapy Resistance May Inform next-Generation Cancer Treatments. Carcinogenesis 2013, 34 (4), 725-738.

(5) Tol, J.; Koopman, M.; Cats, A.; Rodenburg, C. J.; Creemers, G. J. M.; Schrama, J. G.; Erdkamp, F. L. G.; Vos, A. H.; van Groeningen, C. J.; Sinnige, H. A. M.; Richel, D. J.; Voest, E. E.; Dijkstra, J. R.; VinkBörger, M. E.; Antonini, N. F.; Mol, L.; van Krieken, J. H. J. M.; Dalesio, O.; Punt, C. J. A. Chemotherapy, Bevacizumab, and Cetuximab in Metastatic Colorectal Cancer. N. Engl. J. Med. 2009, 360 (6), 563-572.

(6) Miller, K.; Wang, M.; Gralow, J.; Dickler, M.; Cobleigh, M.; Perez, E. A.; Shenkier, T.; Cella, D.; Davidson, N. E. Paclitaxel plus Bevacizumab versus Paclitaxel Alone for Metastatic Breast Cancer. N. Engl. J. Med. 2007, 357 (26), 2666-2676.

(7) Vermorken, J. B.; Mesia, R.; Rivera, F.; Remenar, E.; Kawecki, A.; Rottey, S.; Erfan, J.; Zabolotnyy, D.; Kienzer, H.-R.; Cupissol, D.; Peyrade, F.; Benasso, M.; Vynnychenko, I.; De Raucourt, D.; Bokemeyer, C.; Schueler, A.; Amellal, N.; Hitt, R. Platinum-Based Chemotherapy plus Cetuximab in Head and Neck Cancer. N. Engl. J. Med. 2008, 359 (11), 1116-1127.

(8) Trondl, R.; Heffeter, P.; Kowol, C. R.; Jakupec, M. A.; Berger, W.; Keppler, B. K. NKP-1339, the First Ruthenium-Based Anticancer Drug on the Edge to Clinical Application. Chem. Sci. 2014, 5 (8), 29252932.

(9) Seelig, M. H.; Berger, M. R.; Keppler, B. K. Antineoplastic Activity of Three Ruthenium Derivatives against Chemically Induced Colorectal Carcinoma in Rats. J. Cancer Res. Clin. Oncol. 1992, 118 (3), 195-200.

(10) Bergamo, A.; Gagliardi, R.; Scarcia, V.; Furlani, A.; Alessio, E.; Mestroni, G.; Sava, G. In Vitro Cell Cycle Arrest, in Vivo Action on Solid Metastasizing Tumors, and Host Toxicity of the Antimetastatic Drug NAMI-A and Cisplatin. J. Pharmacol. Exp. Ther. 1999, 289 (1), $559-564$.

(11) Heffeter, P.; Böck, K.; Atil, B.; Reza Hoda, M. A.; Körner, W.; Bartel, C.; Jungwirth, U.; Keppler, B. K.; Micksche, M.; Berger, W.; Koellensperger, G. Intracellular Protein Binding Patterns of the Anticancer Ruthenium Drugs KP1019 and KP1339. JBIC, J. Biol. Inorg. Chem. 2010, 15 (5), 737-748.

(12) Groessl, M.; Zava, O.; Dyson, P. J. Cellular Uptake and Subcellular Distribution of Ruthenium-Based Metallodrugs under Clinical Investigation versus Cisplatin. Met. Integr. Biometal Sci. 2011, 3 (6), 591-599.

(13) Licona, C.; Spaety, M.-E.; Capuozzo, A.; Ali, M.; Santamaria, R.; Armant, O.; Delalande, F.; Van, D. A.; Cianferani, S.; Spencer, J.; Pfeffer, M.; Mellitzer, G.; Gaiddon, C. A Ruthenium Anticancer Compound Interacts with Histones and Impacts Differently on Epigenetic and Death Pathways Compared to Cisplatin. Oncotarget 2016, 8 (2), 2568-2584.

(14) Murray, B. S.; Babak, M. V.; Hartinger, C. G.; Dyson, P. J. The Development of RAPTA Compounds for the Treatment of Tumors. Coord. Chem. Rev. 2016, 306, 86-114.

(15) Scolaro, C.; Bergamo, A.; Brescacin, L.; Delfino, R.; Cocchietto, M.; Laurenczy, G.; Geldbach, T. J.; Sava, G.; Dyson, P. J. In Vitro and in Vivo Evaluation of Ruthenium(II)-Arene PTA Complexes. J. Med. Chem. 2005, 48 (12), 4161-4171.

(16) Adhireksan, Z.; Palermo, G.; Riedel, T.; Ma, Z.; Muhammad, R.; Rothlisberger, U.; Dyson, P. J.; Davey, C. A. Allosteric Cross-Talk in Chromatin Can Mediate Drug-Drug Synergy. Nat. Commun. 2017, 8, 14860 .

(17) Bergamo, A.; Riedel, T.; Dyson, P. J.; Sava, G. Preclinical Combination Therapy of the Investigational Drug NAMI-A(+) with Doxorubicin for Mammary Cancer. Invest. New Drugs 2015, 33 (1), $53-63$.
(18) Goyeneche, A. A.; Carón, R. W.; Telleria, C. M. Mifepristone Inhibits Ovarian Cancer Cell Growth in Vitro and in Vivo. Clin. Cancer Res. 2007, 13 (11), 3370-3379.

(19) Tieszen, C. R.; Goyeneche, A. A.; Brandhagen, B. N.; Ortbahn, C. T.; Telleria, C. M. Antiprogestin Mifepristone Inhibits the Growth of Cancer Cells of Reproductive and Non-Reproductive Origin Regardless of Progesterone Receptor Expression. BMC Cancer 2011, 11, 207.

(20) Breitkreutz, I.; Anderson, K. C. Thalidomide in Multiple Myeloma-Clinical Trials and Aspects of Drug Metabolism and Toxicity. Expert Opin. Drug Metab. Toxicol. 2008, 4 (7), 973-985.

(21) Telleria, C. M. Drug Repurposing for Cancer Therapy. J. Cancer Sci. Ther. 2012, 4 (7), ix-xi.

(22) Kenny, H. A.; Lal-Nag, M.; White, E. A.; Shen, M.; Chiang, C.Y.; Mitra, A. K.; Zhang, Y.; Curtis, M.; Schryver, E. M.; Bettis, S.; Jadhav, A.; Boxer, M. B.; Li, Z.; Ferrer, M.; Lengyel, E. Quantitative High Throughput Screening Using a Primary Human ThreeDimensional Organotypic Culture Predicts in Vivo Efficacy. Nat. Commun. 2015, 6, 6220.

(23) Varbanov, H. P.; Kuttler, F.; Banfi, D.; Turcatti, G.; Dyson, P. J. Repositioning Approved Drugs for the Treatment of Problematic Cancers Using a Screening Approach. PLoS One 2017, 12 (2), e0171052.

(24) Nosengo, N. Can You Teach Old Drugs New Tricks? Nature 2016, 534 (7607), 314-316.

(25) Zhang, J.-H.; Chung, T. D. Y.; Oldenburg, K. R. A Simple Statistical Parameter for Use in Evaluation and Validation of High Throughput Screening Assays. J. Biomol. Screening 1999, 4 (2), 67-73.

(26) Juliana, C.; Fernandes-Alnemri, T.; Wu, J.; Datta, P.; Solorzano, L.; Yu, J.-W.; Meng, R.; Quong, A. A.; Latz, E.; Scott, C. P.; Alnemri, E. S. Anti-Inflammatory Compounds Parthenolide and Bay 11-7082 Are Direct Inhibitors of the Inflammasome. J. Biol. Chem. 2010, 285 (13), 9792-9802.

(27) Nakshatri, H.; Rice, S. E.; Bhat-Nakshatri, P. Antitumor Agent Parthenolide Reverses Resistance of Breast Cancer Cells to Tumor Necrosis Factor-Related Apoptosis-Inducing Ligand through Sustained Activation of c-Jun N-Terminal Kinase. Oncogene 2004, 23 (44), $7330-7344$.

(28) Pajak, B.; Gajkowska, B.; Orzechowski, A. Molecular Basis of Parthenolide-Dependent Proapoptotic Activity in Cancer Cells. Folia Histochem. Cytobiol. 2008, 46 (2), 129-135.

(29) Zunino, S. J.; Ducore, J. M.; Storms, D. H. Parthenolide Induces Significant Apoptosis and Production of Reactive Oxygen Species in High-Risk Pre-B Leukemia Cells. Cancer Lett. 2007, 254 (1), 119-127.

(30) Zhang, S.; Ong, C.-N.; Shen, H.-M. Involvement of Proapoptotic Bcl-2 Family Members in Parthenolide-Induced Mitochondrial Dysfunction and Apoptosis. Cancer Lett. 2004, 211 (2), 175-188.

(31) Harrison, E. F.; Zwadyk, P.; Bequette, R. J.; Hamlow, E. E.; Tavormina, P. A.; Zygmunt, W. A. Haloprogin: A Topical Antifungal Agent. Appl. Microbiol. 1970, 19 (5), 746-750.

(32) Rezabek, G. H.; Friedman, A. D. Superficial Fungal Infections of the Skin. Diagnosis and Current Treatment Recommendations. Drugs 1992, 43 (5), 674-682.

(33) Chou, T.-C. Theoretical Basis, Experimental Design, and Computerized Simulation of Synergism and Antagonism in Drug Combination Studies. Pharmacol. Rev. 2006, 58 (3), 621-681.

(34) Kuzu, O. F.; Nguyen, F. D.; Sharma, A.; Noory, M. Current State of Animal (Mouse) Modeling in Melanoma Research. Cancer Growth Metastasis 2015, 8s1, S21214.

(35) Brunda, M. J.; Luistro, L.; Warrier, R. R.; Wright, R. B.; Hubbard, B. R.; Murphy, M.; Wolf, S. F.; Gately, M. K. Antitumor and Antimetastatic Activity of Interleukin 12 against Murine Tumors. $J$ Exp. Med. 1993, 178 (4), 1223-1230.

(36) Demaria, O.; De Gassart, A.; Coso, S.; Gestermann, N.; Di Domizio, J.; Flatz, L.; Gaide, O.; Michielin, O.; Hwu, P.; Petrova, T. V.; Martinon, F.; Modlin, R. L.; Speiser, D. E.; Gilliet, M. STING Activation of Tumor Endothelial Cells Initiates Spontaneous and 
Therapeutic Antitumor Immunity. Proc. Natl. Acad. Sci. U. S. A. 2015, 112 (50), 15408-15413.

(37) Chong, C. R.; Xu, J.; Lu, J.; Bhat, S.; Sullivan, D. J.; Liu, J. O. Inhibition of Angiogenesis by the Antifungal Drug Itraconazole. ACS Chem. Biol. 2007, 2 (4), 263-270.

(38) Lage, H.; Christmann, M.; Kern, M. A.; Dietel, M.; Pick, M.; Kaina, B.; Schadendorf, D. Expression of DNA Repair Proteins HMSH2, HMSH6, HMLH1, O6-Methylguanine-DNA Methyltransferase and N-Methylpurine-DNA Glycosylase in Melanoma Cells with Acquired Drug Resistance. Int. J. Cancer 1999, 80 (5), 744-750.

(39) Weiss, A.; Berndsen, R. H.; Dubois, M.; Müller, C.; Schibli, R.; Griffioen, A. W.; Dyson, P. J.; Nowak-Sliwinska, P. In Vivo AntiTumor Activity of the Organometallic Ruthenium(II)-Arene Complex [Ru(H6-p-Cymene)Cl2(Pta)] (RAPTA-C) in Human Ovarian and Colorectal Carcinomas. Chem. Sci. 2014, 5 (12), 4742-4748.

(40) Weikel, J. H.; Bartek, M. J. Toxicologic Properties and Metabolic Fate of Haloprogin, an Antifungal Agent. Toxicol. Appl. Pharmacol. 1972, 22 (3), 375-386.

(41) Faião-Flores, F.; Suarez, J. A. Q.; Maria-Engler, S. S.; SotoCerrato, V.; Pérez-Tomás, R.; Maria, D. A. The Curcumin Analog DM-1 Induces Apoptotic Cell Death in Melanoma. Tumor Biol. 2013, 34 (2), 1119-1129.

(42) Palma, J. P.; Rodriguez, L. E.; Bontcheva-Diaz, V. D.; Bouska, J. J.; Bukofzer, G.; Colon-Lopez, M.; Guan, R.; Jarvis, K.; Johnson, E. F.; Klinghofer, V.; Liu, X.; Olson, A.; Saltarelli, M. J.; Shi, Y.; Stavropoulos, J. A.; Zhu, G.-D.; Penning, T. D.; Luo, Y.; Giranda, V. L.; Rosenberg, S. H.; Frost, D. J.; Donawho, C. K. The PARP Inhibitor, ABT-888 Potentiates Temozolomide: Correlation with Drug Levels and Reduction in PARP Activity in Vivo. Anticancer Res. 2008, 28 (5A), 2625-2635.

(43) Kiyohara, E.; Tamai, K.; Katayama, I.; Kaneda, Y. The Combination of Chemotherapy with HVJ-E Containing Rad51 SiRNA Elicited Diverse Anti-Tumor Effects and Synergistically Suppressed Melanoma. Gene Ther. 2012, 19 (7), 734-741.

(44) Lake, R. A.; Robinson, B. W. S. Immunotherapy and Chemotherapy-a Practical Partnership. Nat. Rev. Cancer 2005, 5 (5), 397-405.

(45) Casares, N.; Pequignot, M. O.; Tesniere, A.; Ghiringhelli, F.; Roux, S.; Chaput, N.; Schmitt, E.; Hamai, A.; Hervas-Stubbs, S.; Obeid, M.; Coutant, F.; Métivier, D.; Pichard, E.; Aucouturier, P.; Pierron, G.; Garrido, C.; Zitvogel, L.; Kroemer, G. Caspase-Dependent Immunogenicity of Doxorubicin-Induced Tumor Cell Death. J. Exp. Med. 2005, 202 (12), 1691-1701.

(46) Chen, G.; Emens, L. A. Chemoimmunotherapy: Reengineering Tumor Immunity. Cancer Immunol. Immunother. 2013, 62 (2), 203216.

(47) Green, D. R.; Ferguson, T.; Zitvogel, L.; Kroemer, G. Immunogenic and Tolerogenic Cell Death. Nat. Rev. Immunol. 2009, $9(5), 353-363$.

(48) Fine, J. H.; Chen, P.; Mesci, A.; Allan, D. S. J.; Gasser, S.; Raulet, D. H.; Carlyle, J. R. Chemotherapy-Induced Genotoxic Stress Promotes Sensitivity to Natural Killer Cell Cytotoxicity by Enabling Missing-Self Recognition. Cancer Res. 2010, 70 (18), 7102-7113.

(49) Bajetta, E.; Del Vecchio, M.; Bernard-Marty, C.; Vitali, M.; Buzzoni, R.; Rixe, O.; Nova, P.; Aglione, S.; Taillibert, S.; Khayat, D. Metastatic Melanoma: Chemotherapy. Semin. Oncol. 2002, 29 (5), 427-445.

(50) Peng, R.-Q.; Chen, Y.-B.; Ding, Y.; Zhang, R.; Zhang, X.; Yu, X.J.; Zhou, Z.-W.; Zeng, Y.-X.; Zhang, X.-S. Expression of Calreticulin Is Associated with Infiltration of T-Cells in Stage IIIB Colon Cancer. World J. Gastroenterol. 2010, 16 (19), 2428-2434.

(51) Magnarin, M.; Bergamo, A.; Carotenuto, M. E.; Zorzet, S.; Sava, G. Increase of Tumour Infiltrating Lymphocytes in Mice Treated with Antimetastatic Doses of NAMI-A. Anticancer Res. 2000, 20 (5A), 2939-2944.

(52) Hato, S. V.; Khong, A.; de Vries, I. J. M.; Lesterhuis, W. J. Molecular Pathways: The Immunogenic Effects of Platinum-Based Chemotherapeutics. Clin. Cancer Res. 2014, 20 (11), 2831-2837.
(53) Apetoh, L.; Ghiringhelli, F.; Tesniere, A.; Obeid, M.; Ortiz, C.; Criollo, A.; Mignot, G.; Maiuri, M. C.; Ullrich, E.; Saulnier, P.; Yang, H.; Amigorena, S.; Ryffel, B.; Barrat, F. J.; Saftig, P.; Levi, F.; Lidereau, R.; Nogues, C.; Mira, J.-P.; Chompret, A.; Joulin, V.; Clavel-Chapelon, F.; Bourhis, J.; André, F.; Delaloge, S.; Tursz, T.; Kroemer, G.; Zitvogel, L. Toll-like Receptor 4-dependent Contribution of the Immune System to Anticancer Chemotherapy and Radiotherapy. Nat. Med. 2007, 13 (9), 1050-1059. 